\title{
On Cross-cultural Pragmatic Failures in C/E Interpretation
}

\author{
Xuedong Shi \\ Foreign Language Department, Beijing Information Science \& Technology University, Beijing, China
}

\begin{abstract}
Cultural and pragmatic factors are quite often ignored in the interpretation analysis and practice for a long time. At the same time, in the complicated process of interpretation, the lack of interpreters' cross-cultural consciousness gives rise to pragmatic failures which may lead to misunderstanding and even communication breakdowns. The study of interpretation has long been confined to linguistic competence and interpretation skills for a long time. This paper probes into the pragmatic failures in the Chinese and English interpretation practice.
\end{abstract}

Index Terms - culture, pragmatic failures, interpretation

\section{INTRODUCTION}

Interpretation has been used in every walk of life with China's opening up and the world's economic globalization. For this reason, interpreters, the bridges between the different countries and different cultures, must improve their language abilities to meet the requirements to ensure the communication with their bilingual talents and high-demanded skills. Despite their sound knowledge of grammar, semantics and syntax, pragmatic failures are so pervasive among Chinese learners of English and even the interpreters. It is not a rare case that an interpreter may confuse "of course" with "certainly", which have quite different pragmatic implications in different situations. It is also not unusual for a Chinese employee in a joint venture to address his/her colleague as "Old Wang" and the American associate as "Miss Mary". He seems to be quite uneasy and replies "No, no, you flatter me" when praised by his American boss for the job well done. He says, out of sincere care, "Be careful" to the department manager when the manager is getting into a car. What he says is semantically and grammatically perfect, but unfortunately is bound to spoil the situation because his utterances are pragmatically out of place.

However, for a long time, in the interpreter training the importance has been attached to the linguistic focus, namely, vocabulary, grammar, listening comprehension, memorizing, pronunciation and note-taking etc. because they are the standards to judge the language fluency. Unfortunately, even though the interpreters are linguistically qualified, they still tend to fail in the cross-cultural interpretation due to the misunderstanding of the cultural and pragmatic differences between the target language and source language.

\section{CRoss-CUlture COMmunication}

\section{A. $\quad$ Culture}

1. The concept of culture

Culture can be found its existence everywhere in the society, exerting tremendous influence in a substantial way. So we can conclude that every aspect of human life is influenced and touched by culture due to its omnipresent characteristic. At the same time, the definitions of culture have never been achieved due to culture's all-pervasive quality. That is why over 160 definitions of culture found since 1952 in the anthropology literature. At the same time, a lot of new definitions have come into existence every since. All the definitions include the patterns of behavior and thought, artifacts and so on.

2. The characteristic of culture

Though we have never reached a specific definition about culture, there would have been multitude of agreements with regard to the main qualities of culture. Anthropologically, the cultural definitions agree on the following qualities:

(1) Culture is commonly shared

If a man thinks or does a certain thing, his thought and action will represent his personal habit. Similarly, the pattern of culture does so. That is to say, if we consider a thought or action culturally, it must be shared by a large number of people instead of the individuals.

(2) Culture is learned

In spite of that, not all the things shared by groups of people can be called culture. For example, the typical complexion is not cultural. Culture must be learned and shared if we want to define it.

(3) Culture is integrated

Every aspect of culture is tangled up with the other aspects in culture--- it functions as a whole. If one part of culture is touched, everything else of culture will be influenced and touched. For instance, family size and spiritual outlook will 
be influenced by the material values in a culture.

(4) Culture is based on symbols

Language is a kind of symbol, which includes a lot of entities and events that cannot be caught alone. This kind of thought has been proved by many anthropologists who think that language is the carrier of culture. To be more specific, a culture without language is unbelievable.

3 . The classification of culture

Culture can be divided into the following four sub-systems according to an anthropological standard.

(1) Techno-economic system: Techno-economic System: ecology, means of production, exchange and distribution of goods, crafts, technology and science and artifacts.

(2) Social System: social classes and groups, kinship system, politics and law, education, sports and entertainment, customs and general history.

(3) Linguistic System: phonology and graphemes, morphology and syntax and pragmatics.

(4) Ideational System: cosmology, religion, magic and witchcraft, folklore, artistic creations as images, values, cognitive focus and thinking patterns, and ideology.

In the above-mentioned four sub-systems, the ingredients are varied from culture to culture. So when translators want to solve the cultural gap between the source language and target language, some misreading will arise accordingly.

\section{B. Cultural Communication}

\section{Culture and communication}

Mentioned about communication, most people will think about language, though it is only one essential part in fact. Rather, we can communicate with others in many ways about our thoughts, feelings, desires and wishes etc. At the same time, communication can be in other forms expert for verbal communication--- none verbal communication, without using words: facial expressions, hand gestures, posture, body orientation, tone of voice, pitch, intonation, interpersonal space, touching behavior and so on. Similar to verbal actions which are affected by the culture, the nonverbal actions are still influenced by the cultural models which got from the social contacts.

Owning to the cultural differences, communications which are brought up in different cultures are variable too. At the same time, the culture-communication relationship is reciprocal----- affecting and influencing each other all the time. For example, the subjects we are talking about, the way we are talking about are decided by our culture. In turn, these ingredients will influence or even permeate the culture. That is to say, language and culture are co-existent instead of isolation. We can compare communication to swimming, langue swimming skill and culture water. Without culture, communication cannot exist at all because one cannot swim without water. Since we cannot separate language, culture and communication respectively, we can draw a safe conclusion that the three factors are closely interrelated. Language is the carrier of culture and it can be used to communicate. Thus without a good command of the different cultures knowledge, communication will fail and understanding cannot be reached. In one word, communication via language cannot be reached without a good cultural learning in different cultures.

2. Barrier in cross-cultural communication and their causes

The main obstacles in the cross-cultural communication can be classified as cognition, stereotype and ethnocentrism mistakes (Hu, 1994). First, people from different cultural backgrounds live an illusion that there is no difference between them in cross-cultural communication. Therefore, they will try to interpret or translate others on the view of their own cultural background. This kind of mistake can be called cognition mistakes. The cognition mistakes are the source of the cross-cultural failures in the end. Thus we should be aware of the fact that different people are the premises of the different cultural grounds and customs. To be more specific, we should develop a kind of cultural consciousness that our culture is different from others. At the same time, we may have a kind of stereotyped impression of the other cultures, even though we have never contacted with them. The examples of that can be find many words to describe a nation, for examples, romantic French, free Americans and hard-working Japanese. The stereotypes have merits and demerits in many ways. The worst of that is that when your stereotype deprives you of your cultural sensitivity and subjective interpretation of another culture. Because of that, it will damage the relationship with others and be harmful to our cross-cultural communication. Though in cross-cultural communication stereotypes are regarded as mixed-blessings, we cannot totally steer clear of them when we talk about cultural differences. The reason is quite simple, in the discussion of cultural differences, summarization, which bears a close resemblance with stereotypes. For example, if you hear people say that Americans are quite brave to tell their private opinions. This kind of observation will be found in books or newspapers on cross-cultural communication. These kind of observation can be called stereotypes. In this aspect, we should pay attention to the individual differences instead of interpreting things from the stereotypes. At the same time, the definition of ethnocentrism means to evaluate everything in other cultures from the angle of the own culture. In the civilized world few people dare to utter that their cultures are superior to others'. But that does not mean that they do not evaluate other cultures with their own standards subconsciously. Because ethnocentrism coexists with culture, some scholars state that no one can avoid it. In the process of cross-cultural communication, the main obstacles have been mentioned though some others are being left out of attention.

Since cultures vary in different societies, the essential feature is that the culture is learnt and acquired. Culture is usually got through education in which an older generation compels the younger one to establish a kind of lifestyle; therefore, culture is rooted in a person's life style. At the same time, culture is difficult to define because it appears at an 
unconscious level. Just because of this deep-rooted reason, it leads to many serious problems in communication. People from one cultural community will find it difficult to accept the things which are regarded as quite proper in another culture. Another potential cause of cultural difference is the cultural prejudice or the cultural arbitrary. That is to say that the one-to-one reflection between the language form and object shape the language reflects. (Levinson, 2001)

Qian Guanlian describes the phenomenon as no two languages can be qualified to take the responsibility to represent the same reality socially. At the same time, language arbitrariness is also the reason for language variation in difficult cultures. (Qian, 2008) Different language speakers will make the sounds of the language mixed to communicate and use different structural patterns at the same time. The expression is influenced by the different concepts in various cultures. For example, the pure white in Chinese language is described as snow, and the Chinese people will use the term xuebai, meaning as white as snow, while the counterpart expression in English is as white as bed sheets.

English and Chinese are totally different just because they are arising from the two totally different cultures. Among them, natural environment and social environment are the two primary elements for forming the differences in the language evolution history. In this process, the two languages have been playing a very important role in forming the two languages, the representatives of the eastern and western culture.

\section{PRAgMatic FAILURE}

1. What is pragmatic

We should winkle out the originality of the pragmatics if we want to understand the pragmatic failure development. The term pragmatics is a very important interdisciplinary study on interpretation. Pragmatics was not regarded as a independent subject with the journal of pragmatics came into existence in 1977. And in 1983 the International Pragmatics Association was founded and this marked the maturity of the pragmatics. (Newmark, 2001) Fortunately, pragmatics study has developed very quickly in the past two decades and has achieved a lot in spite of the short history. At the same time, pragmatics study has witnessed some new born interdisciplinary studies: inter-language pragmatics, social pragmatics, cross-cultural pragmatics, developmental pragmatics and cognitive pragmatics etc. Pragmatics study's central part is the study of words and its language in the context, which is a new study branch in linguistics. Though its own conception should be given to pragmatics as any other terms, it is far from easy to definite pragmatics in an exact and precise way. In different books, a great many definitions can be found and many linguists have given their own definitions in various situations. Mey gives his definition of pragmatics and has been widely accepted as it is a kind of language way and that can be seen in relation to the language speakers. (Mey, 1993) Also, Leech, the famous linguist, makes his contribution to pragmatics by dividing it into two types: sociopragmatics and pragmalinguistics. The former type refers to the study of the language use in the society, while the latter type refers to the utterance meaning in the social characteristics. At the same time, sociopragmatics tends to study in a broader way, covering the language use criteria and making language a communicative tool in various contexts and situations. Besides that, sociopragmatics lays its emphasis on many other studying areas, say, the characteristics of the language speakers who come from the different cultural backgrounds and how to behave in language learning. On the other hand, another type, pragamalinguistics focus on the study on the problems of language pragmatic problems----- the relationship between the language forms and functions in pragmatics. Vocabulary, phonetics, grammar, discourse and rhetoric, all these mentioned forms in language are within the study areas of pragmalinguistics.

2. Definitions of pragmatic failure and causes of pragmatic failures in interpretation

Pragmatic failures can be traced by to its original study and in China they can be found in a specific way as a correct sentence in grammatical way but has broke a kind of hidden or unconscious rule, conventions or without noticing the addressers, space or time etc. (Qian, 2008)

As the social and cultural image, language must be co-existent with a kind of certain cultural background---- every language is a carrier of a kind of language. As we have mentioned above, similar to the huge differences of the human society cultures, human languages are the source of many differences. For the people from the difficult cultural backgrounds, they cannot communicate without encountering the pragmatic differences, arising from their cultures. This paper will focus on the English and Chinese pragmatic difference in the following part.

a. Pragmatic failures due to social and custom distinctions

Sometimes most of the sociopragmatic failures in the Chinese and English interpretations result from the ignorance of the huge difference between the two languages in the cultural and social aspects. Among them, most of the failures are about the taboo topics, utterances register and the social identities. This kind of failure is often the source of communicative breakdown and bad public relationship. For example, despite of the different social status and ages, the English speakers will call others' names directly with the aim of showing their intimate relationship and people's equality. On the contrary, the native speakers may feel that the addressing words as manager or director before the names show the lack of willingness to be intimate to others. Rather, Chinese people will feel embarrassed, at least unnatural, to call others given names. Because of this, the interpreters can use other expressions like Mr. John or Mrs. Brown to address the people from the English-speaking countries.

b. Pragmatic failures due to image patterns

As we know, the Chinese dragon or the oriental dragon, which originated from China, is a mythical symbol in East Asian culture. In the Chinese culture, the oriental dragon has been described as a snake-like, scale animal with five 
claws and four legs. The oriental dragon has long been the symbol of royal families in China, standing for power and authority. Quite different from the Chinese tradition, the western dragon is the symbol of evil. Considering about that, the dragon position in Chinese can be decoded into the throne, the dragon gown in Chinese can be decoded into the emperor gown, the dragon chair can be decoded into the royal chair and the dragon hat can be decoded into crown.

c. Pragmatic failures derived from different world perceptions

To the same object, the people from the different countries and cultures view from the different angles because of the existing customs in their minds. But the misunderstandings and obstacles may stem from the cultural differences in the process of cultural communications of the two languages. Among them, values and religion are two important elements to the forming of the outlook. The sad truth is that the religious beliefs vary greatly between China and western English speaking countries. For example, English speakers are quite religious and they have a faith in God, they cherish the individualism and they are sensitive to the individual rights. On the contrary, Chinese counterparts follow the religion of Taoism and Buddhism. At the same time, collectivism is their primary concern. This kind of cultural differences may lead to misunderstanding even the cultural barriers in communication. Considering that, the Chinese typical saying of greeting: where are you going is beyond understanding for the people from English-speaking countries, who think their privacy cannot be offended.

d. Pragmatic failures due to different mentality and thinking patterns

As two large civilization origins in the world, the communication between Chinese and western English speaking countries really deserves close study. Then in a healthy global culture, the ideal condition is that each participating number is equal and not one is marginalized. Similarly, all cultures should be equal so that most cultural members can have a chance to acquire it. Considering all the things mentioned above, all of the cultures should participate the cultural system though it has its merits and demerits, thus it can make its own contribution to the global culture.

\section{Tentative Solutions to Intercultural Pragmatic FAILURES In InTERPRETATiOnS}

According to Newmark, cultural stereotype can still be use as a tool to uplift the cultural awareness of the interpreters from the primary level to higher level, though it has been over simplified and universalized, because it can help the translators to develop the cultural difference sensitivity. (Newmark, 2001) At the same time, as a qualified interpreter, he or she is should expose himself/herself to the source language culture just like to the simple fact that the more you read, the more chances you have to be familiar with the native's mentality. Besides that, interpreters should be home at collecting and summarizing all of the differences about culture which they have felt in the practice of interpreting or when they communicate with the native speakers from English-speaking countries. Of course, in the interpreting teaching practice, the trainers should enable their students having this kind of sensitivity to cultural differences by letting them know the method of contrastive cultural studies.

As has been mentioned in the above chapters, the Chinese and English cultural differences may cause pragmatic failures in the interpretation practice. However, interpretation cannot exist without language--- they go hand in hand. These two elements are inflecting each other all the time at any place because language is represented by its culture. Thus, interpretation plays an important part in the communication in cross-cultural aspect. To avoid pragmatic failures, the interpreters should bear in mind that they should have the cultural difference sensitivity all the time.

A qualified interpreter should have the consciousness to the different cultures in order to avoid cross-cultural failures. Being home at the cultural backgrounds and customs in different cultures is their job, at the same time, being home at the language habits and cultural backgrounds every time he gets the opportunity. Being aware of the differences and similarities is not enough, they should make adjustments according to the different cultural backgrounds. To do that, a good interpreter should put the knowledge he learnt into practice.

1. Cultivating and enhancing cross-cultural communicative competence

Cross-cultural communication refers to the exchange of knowledge, concepts and thoughts among the people from the various cultural backgrounds. (Linen, 2004) accordingly, cross-cultural communication happens when the people from the different cultural backgrounds meet each other. Then, the cross-cultural communicative competence is a kind of action that is proper and effective in a certain or given context. (Gile, 1993) The effective outcome from the cross-cultural communication is the standard to judge the communication competence in different situations. At the same time, cross-cultural commutative competence can be divided into two classes or two fields, namely, the linguistic and pragmatic competence. (Eugene, 1993). For the first class, linguistic aspect consists of three factors: grammar, lexicon and phonology; rather, for the pragmatic aspect, the dominating part of communicative competence, is kind of capability to choose a linguistic form which is right or proper for the specific communicative situation---using English or Chinese properly in the social communicative interactions. As has been found, the acquirement of pragmatic competence of a target culture starts the moment a student is exposed to it. (Hatim, 1997) And that is why both the teachers and students can improve this kind of communicative competence by developing the cross-cultural consciousness.

2. Developing pragmatic competence

First of all, for English learners or interpreters, pragmatic principles can be introduced to them. To be more specific, linguistic knowledge is essential in English learning, but knowing how, when and where to apply the linguistic knowledge in anther cultural context weighs more. That is say, pragmatic teaching is of necessity. Pragmatics can be 
divided into pragmalinguistics and sociopragmatics. (Leech, 1983) Accordingly, the pragmatic competence can be divided into the pragmalinguistic and sociopragmatic competence. The former is on the premises of grammatical competence, dealing with the language rules in use, such as the wording and phrasing; the latter is on the premises of language uses in social aspect, which is a higher level. Despite of the different explanations, the pragmatic competence focuses on one point---- the right or proper communication. (Eugene, 1993) Thus, the decency and properness require the competence of understanding, expressing and context controlling. The tree competences are interrelated to each other and they are quite essential for the smooth cross-cultural communication. The comprehending competence depends on context controlling while the comprehending competence can enhance the competence of expression of text.

\section{CONCLusion}

Language is the carrier of the culture, while culture is carried all the time by language in communication. Interpreters are charged with essential task in a cross-cultural situation where two people from the different language and social backgrounds, try to express themselves with no knowledge of the different cultures. It is the interpreters job to translating their information, both linguistic and cultural, from one language to another. To be more specific, interpreters can be compared to bridges of language and culture between the gaps of the two people, who are ignorant of his counterpart's language and culture. In this article, it is my standpoint that the competent interpreters cannot achieve their aims without knowing the pragmatic differences between English and Chinese. To sum up, it is of great importance for qualified interpreters to be conscious of the pragmatic differences.

\section{REFERENCES}

[1] Eugene A. Nida. (1993). Language, culture, and translation: Shanghai: Shanghai Foreign Language Education Press.

[2] Gile, Daniel. (1993). Basic Concepts and Models. Amsterdam/Philadelphia: John Benjamin Press

[3] Hall Edward T. (1976) Beyond Culture. New York: Doubleday \& company.

[4] Hanvey, Robert G. (1976). An Attainable Global Perspective, New York: Center for Global Perspectives.

[5] Hatim, B. (1997). The Translators Communicator. London: Routledge.

[6] Hofstede, Geert. (1991). Cultures and Organizations: Software of the Mind. New York: Mc Graw Hill.

[7] Hu, Wenzhong. (1994). Culture and COmmuicaiton. Beijing: Foreign Language Teaching and Research Press.

[8] Katan, David. (2004). Translating Cultures: An Introduction for Translators, Interpreters and Mediators Shanghai: Shanghai Foreign Language Education Press.

[9] Leech, G. (1983). Principles of Pragmatics. New York: Longman Group Limited.

[10] Levinson, S.C. (2001). Pragmatics. Beijing: Foreign Language Teaching and Research Press

[11] Liddicoat, Crozet. (1999). Striving for the Third Place: Intercultural Competence though Language Education. New York: Doubleday \&company.

[12] Linen Davis. (2004). Doing Culture Cross -Cultural Communication in Action. Beijing: Foreign Language Teaching Press.

[13] Mey, J.L. (1993) Pragmatics: An Introduction. Beijing: Foreign Language Teaching and Research Press.

[14] Newmark, P. (2001) A Textbook of Translation. Shanghai: Shanghai Foreign Language Education Press

[15] Qian, Guanlian. (2008). Qian Guanlian's Anthology on Linguistics: Theories and Methodologies. Beijing: Foreign Language Teaching and Research Press.

[16] Witte. H. (1996). Contrastive Cultural Learning in Translator Training. Amsterdam: John Benjamins Publishing Company.

[17] Yule, G. (2000) Pragmatics. Shanghai: Shanghai Foreign Language Education Press.

Xuedong Shi was born in Huhhot, Inner Mongolia, China in 1974. He received his MA degree in translation in Middlesex University, Britain, in 2004. He is currently a lecturer in the Foreign Language Department, Beijing Information Science University, Beijing, China. His academic research mainly focuses on translation and applied linguistics. 